\title{
Educação Literária em Português-alargando horizontes lusófonos
}

\section{Carla Alexandra do Espírito Santo Guerreiro ${ }^{a}$,}

${ }^{a}$ Instituto Politécnico de Bragança, Bragança, Portugal.carlaguerreiro@ipb.pt

\begin{abstract}
Resumo
Apresentaremos uma abordagem pedagógica implementada no Ensino Superior, desenvolvida no âmbito da unidade curricular de Literaturas e Culturas Lusófonas-I, que visa a educação estético- literária dos alunos do 1. ${ }^{\circ}$ ano do Curso de Licenciatura em Relações Lusófonas e Língua Portuguesa, com particular incidência nos alunos de países africanos de lingua oficial portuguesa: S.Tomé, e Cabo-verde.

O nosso objetivo primordial foi dar a conhecer, aos discentes, autores lusófonos das várias latitudes onde a língua portuguesa é falada, tendo tido particular preocupação em que os alunos africanos conhecessem autores clássicos e contemporâneos do cânone literário brasileiro e português (respeitando o programa daunidade curricular), tendo procedido previamente à seleção de um corpus autoral canónico e propondo o seu estudo diacrónico. Na implementação do projeto partimos de uma análise dos curricula do ensino secundário dos paises de origem dos alunos que maioritariamente constituíam a turma (Cabo Verde e S.Tomé), a fim de que as aprendizagens propostas fossem interessantes e significativas para os mesmos.
\end{abstract}

Utilizámos uma metodologia baseada na leitura textual, análise literária e pesquisa bibliográfica e de cruzamento de dados e, para aferir a importância desta abordagem no ensino/aprendizagem da literatura lusófona, aplicámos um questionário semi-estruturado aos catorze alunos que constituíam a turma, podendo aferir o sucesso e consecução dos objetivos delineados.

Palavras-chave: Literatura, Lusofonia, Leitura

\section{Introdução}

A unidade curricular de Literaturas e culturas lusófonas-I integra o currículo do $1 .^{\circ}$ ano da Licenciatura em Relações Lusófonas e Língua Portugue-ramo: Português Língua Materna. 
Podem candidatar-se a esta Licenciatura, através de concurso nacional, os estudantes titulares do 12..$^{\circ}$ ano de escolaridade ou equivalentes e estudantes provenientes de sistemas de ensino secundário (ou equivalente) estrangeiros ao abrigo do Estatuto do Estudante Internacional; os estudantes provenientes de sistemas de ensino superior estrangeiro; os estudantes provenientes do sistema de ensino português, por reingresso, mudança de curso e transferência; os titulares de Cursos Médios ou Superiores; os titulares de um Curso de Especialização Tecnológica; ou os alunos maiores de 23 anos que tenham realizado exame extraordinário de avaliação de capacidade para acesso ao Ensino Superior. As condições de acesso ao $1 .^{\circ}$ Ciclo de Estudos do Ensino Superior (Licenciatura) constam da descrição do Sistema de Ensino Superior Português, disponibilizada pelo NARIC (http://www.dges.mctes.pt/DGES/pt/Reconhecimento/NARICENIC/) e apresentada na secção 8 do Suplemento ao Diploma. Os detentores do título de licenciatura estão habilitados para a candidatura à carreira técnica superior da administração pública e aos quadros de organizações privadas e para o desenvolvimento de atividade independente nos países lusófonos.A maior parte dos 14 alunos da turma do ano letivo de 2019/2020 é constituída por alunos dos PALOPs (países africanos de língua oficial portuguesa), nomeadamente oriundos de S. Tomé e Cabo Verde, que apresentam um conhecimento muito reduzido de autores e literatura de expressão lusófona, que como docente da unidade curricular de : Literaturas e Culturas Lusófonas-I, senti necessidade de colmatar.

\section{O Ensino Secundário em S. Tomé e Cabo Verde}

São Tomé e Príncipe herdou um sistema de educação colonial marcado por grande analfabetismo, existência de uma única escola de Ensino pós-primário e ausência de Ensino Profissional. Já no período da independência deste país houve um alargamento do Ensino Básico obrigatório até à $6 .^{\mathrm{a}}$ classe e, nos últimos anos, tem-se verificado a sua universalização. Também o Ensino Secundário (da 7. à 11. a classes) tem vindo a ser alargado e hoje existe o $1 .^{\circ}$ Ciclo do Ensino Secundário (7. à 9. ${ }^{\mathrm{a}}$ classes) em todos os distritos (Água Grande, Me-zochi, Lobata, Lembá, Cantagalo, Caué) e na região autónoma do Príncipe. O 2. ${ }^{\circ}$ ciclo do Ensino Secundário está circunscrito ao Liceu Nacional de São Tomé e à Escola do Príncipe. O Ensino Secundário, desde a independência do país, vem sendo apoiado pela cooperação portuguesa, traduzindo-se fundamentalmente esse apoio na lecionação de professores cooperantes no Liceu Nacional e a partir de 2006-2007 na implementação de cursos profissionalmente qualificantes. A partir de 2009 esta forma de cooperação foi aprofundada pela atribuição da tarefa de colaboração com o Ministério da Educação e Cultura (MEC) na implementação da reforma do Ensino Secundário, no seguimento da reforma do Ensino Básico, em curso desde 2004. Uma das linhas que consideramos 
fundamental foi a da reformulação e fixação do plano de estudos e programas do Ensino Secundário. Como metodologia de trabalho para a conceção do plano de estudos e dos programas, o projeto recorreu aos agentes da cooperação portuguesa e a docentes sãotomenses com experiência na lecionação. O resultado do trabalho realizado foi aferido por uma equipa externa. Como dimensões fundamentais da reforma curricular indicamos: (i) Manutenção de dois ciclos do ensino secundário: $10^{\circ}$ da 7. à 9. ${ }^{a}$ classes e $2 .^{\circ}$ da $10 .^{a}$ à $12 .{ }^{a}$ classes;(ii) Manutenção de cursos de ensino geral e criação de cursos de educação profissional nos dois ciclos de ensino; (iii) Definição em todos os cursos das componentes de formação geral (Língua Portuguesa, Francês, Inglês, Matemática, Educação Física, no Primeiro Ciclo e Língua Portuguesa, Língua Estrangeira, Educação Física, Integração Social e Filosofia no segundo ciclo) de formação específica e de formação tecnológica; (iii) Introdução do sistema de avaliação continua da aprendizagem (avaliação sumativa interna da aprendizagem é da responsabilidade do conselho de turma com base na proposta do docente e concretiza-se na atribuição de classificações no final dos $1 .^{\circ}, 2 .^{\circ}$ e $3 .^{\circ}$ períodos letivos sendo as duas ultimas resultado de $40 \%$ da classificação atribuída no período anterior) e (iiiii) Definição de áreas de enriquecimento curricular no $1 .^{\circ}$ ciclo do ensino secundário; Como vêmos nenhuma disciplina de Literatura foi criada para integrar o currículo do Ensino Secundário e, portanto, os alunos apenas tomam conhecimento dos textos que são estudados em Língua portuguesa, abordados numa perspetiva funcionalista da língua.

No caso cabo-verdiano, a reestruturação do Ensino Secundário encontrou os seus fundamentos legais nos princípios consagrados na Lei de Bases do Sistema Educativo (LBSE). Lei $n^{\circ}$ 103/III/90 de 29 de Dezembro, a qual define, no artigo 100, os objetivos da política educativa para o Ensino Secundário. Define ainda a Lei no artigo $23^{\circ}$ que o Ensino Secundário tem a duração de seis anos organizando-se em três ciclos de dois anos cada. No artigo $24^{\circ}$ explicita-se que o $1^{\circ}$. Ciclo - Tronco Comum - visa, pela sua organização curricular aumentar o nível de conhecimentos e possibilitar uma orientação escolar e vocacional, tendo em vista o prosseguimento de estudos, uma vez que no termo deste $1 .{ }^{\circ}$ Ciclo, os alunos poderão optar pela via geral ou pela via do Ensino Técnico. Por sua vez o artigo $26^{\circ}, 3.4$. afirma que, relativamente à via do Ensino Secundário Geral, no $2 .^{\circ}$ ciclo são aprofundados e alargados os conhecimentos e aptidões obtidos no ciclo anterior, enquanto que o $3 .^{\circ}$ ciclo se organiza por áreas, visando a inserção na vida ativa ou o prosseguimento de estudos, no Ensino Superior. O plano de estudos para cada um dos três ciclos é constituído por uma grelha de disciplinas não perfeitamente coincidentes nos dois anos que o constituem, com cargas horárias elevadas ao máximo possível, dentro do condicionalismo maior do funcionamento das escolas em regime duplo. Áreas curriculares consideradas essenciais, tais como: Línguas, Matemática, Educação Física e Formação Pessoal e Social desenvolvem-se em todo o percurso escolar. 
Como podemos constatar, neste plano de estudos, tal como no santomense, não está contemplada a área científica de Literatura, mas apenas a de Língua Portuguesa. Além do mais, o deficiente domínio da Língua Portuguesa e o insucesso escolar dele decorrente são consequência da metodologia utilizada no ensino dessa língua em Cabo Verde.Efetivamente o português foi ministrado, até ao início da generalização da Reforma do Ensino Básico como se se tratasse da língua materna. Privilegiou-se o estudo do funcionamento da língua em si como um instrumento linguístico previamente conhecido e, nessa linha, os conteúdos gramaticais ocupavam a maior parte dos programas do Ensino Secundário. No entanto, sabemos que a maior parte dos caboverdianos falam criolo, desta forma, a aquisição e o desenvolvimento de competências com vista à utilização prática da língua, oral e escrita pressupõem a adoção de uma outra metodologia, própria do ensino/aprendizagem de uma língua estrangeira iniciada no Ensino Básico e retomada no Secundário.Neste sentido, a nova metodologia privilegia a comunicação interativa, a qual provoca o adequado comportamento linguístico em situações diversificadas e põe ênfase no treino e desenvolvimento de aptidões de comunicação verbal - compreensão e expressão da linguagem oral e escrita - nas suas várias formas. Ou seja, os textos estudados na aula de Língua portuguesa, são-no apenas de um ponto de vista da funcionalidade ou pragmática da língua, não sendo abordados aspetos estilísticos ou retóricos da mesma.

\section{Literaturas e Culturas Lusófonas-I e o projeto:Lusofonia(s)}

A unidade curricular de Literaturas e Culturas Lusófonas-pretende preparar o aluno para (i)Analisar e interpretar recursos expressivos da linguagem literária, relacionando textos com os seus contextos, mediante a natureza, função, organização e estrutura das manifestações literárias; (ii) Perceber as relações de caráter interativo existentes entre a literatura, a cultura em geral e a história; (iii) Entender o texto literário da sua e de outras épocas também como reflexão sobre a relação ser-mundo, possível de ser atualizada e recontextualizada. De forma a responder a estes três objetivos, delineámos o programa da UC que a seguir apresentamos:

1. Trovadorismo-Lirismo amoroso nas cantigas de amor e de amigo;

2. Teatro medieval-"O Velho da Horta", de Gil Vicente;

3. Classicismo-Amor e desconcerto do mundo nos sonetos de Camões;

4. Barroco-Lirismo (religioso e amoroso) e a sátira de Gregório de Matos Guerra;

5. Arcadismo-Poemas líricos de Bocage;

6. Romantismo-Leitura de poemas de Gonçalves Dias e de Castro Alves;

7. Realismo-Leitura de excertos textuais de obras de Machado de Assis e de Eça de Queirós; 
8. Parnasianismo-Lirismo na poesia de Olavo Bilac;

9. Simbolismo-Leitura de poemas de Camilo Pessanha e Cruz e Sousa;

10. Modernismo -Leitura de excertos textuais de Fernando Pessoa e Carlos Drummond de Andrade;

11. Literatura Contemporânea- Clarice Lispector e José Saramago.

Como a maior parte dos alunos não teve a disciplina de Literatura, nos seus curricula do Ensino Secundário, nos seus países de origem, decidimos contribuir para o alargamento do seu conhecimento nesta área, de forma dinâmica e apelativa, propondo-lhes a leitura de um corpus autoral de expressão lusófona de diferentes épocas históricas e geografias, projeto que denominámos como: Lusofonia(s)

Propusemos a leitura de diferentes autores lusófonos, tendo tido a preocupação de atribuir a cada um dos alunos autores de uma nacionalidade diferente da de cada um deles. O corpus autoral proposto consistiu nos seguintes autores: Pepetela, Mia Couto, Clarice Lispector, Miguel Torga, Jorge Amado,António Pires Cabral e José Eduardo Agualusa.Cada aluno desenvolveu um projeto de investigação individual, escolhendo, com a nossa ajuda, uma obra representativa de cada um dos autores atribuídos e leu-a e analisou-a, de acordo com um guião fornecido pela docente e, num último momento do semestre, cada aluno fez a apresentação do seu projeto de leitura, investigação e análise, aos restantes colegas.As metodologias apresentadas foram diversas, desde a apresentação oral com suporte de imagens à apresentação em powerpoint ou prezi, sempre ao critério de cada aluno, contando com o apoio da docente.Para avaliar este projeto, aplicamos um questionário semiestruturado, que nos permitiu avaliá-lo, concluindo da utilidade e sucesso do projeto.

\section{Conclusões sobre o projeto Lusofonia(s)}

O questionário foi aplicado dia 22-1-2020 a catorze alunos,passando,agora, a apresentar apenas os diagramas representativos das respostas que consideramos mais importantes para avaliar o projeto e concretamente a sua utilidade e sucesso.

Assim, relativamente ao universo de alunos avaliados, sobre a sua nacionalidade e se a disciplina de literatura constara anteriormente no seu currículo escolar,apresentamos as figuras 1 e 2 . 
Qual a sua nacionalidade

14 respostas

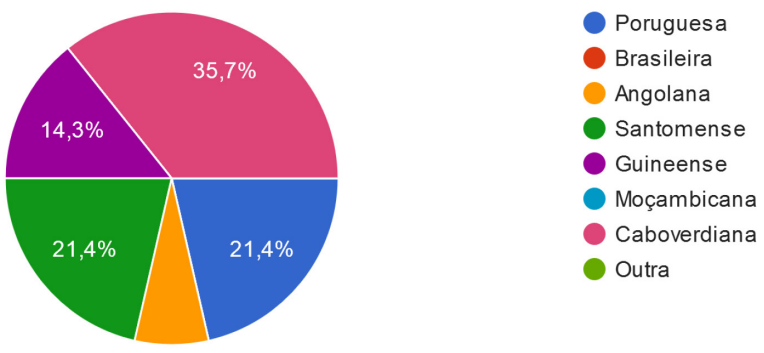

Fig. 1

Assinale, no quadro abaixo, as disciplinas que teve no Ensino Secundário ou equivalente.

14 respostas
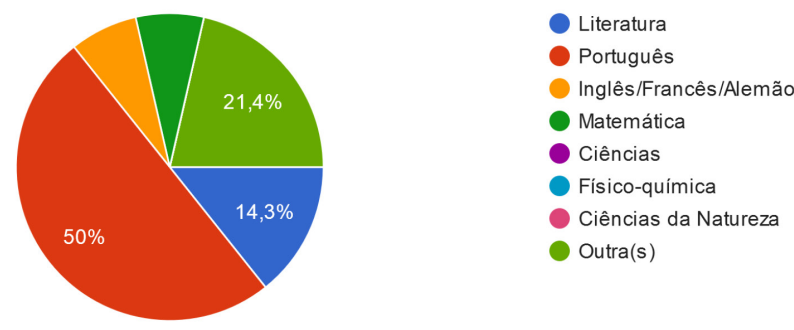

Fig. 2

Como comprovamos, a maioria dos alunos que frequenta o $1 .^{\circ}$ ano do curso é de nacionalidade africana, apenas contando com uma percentagem de $21, \%$ portuguesa e a larga maioria dos alunos da turma nunca teve a disciplina de Literatura portuguesa-78,6\%, tendo sido o nosso desafio,claramente acrescido.

4- Dos autores estudados, na unidade curricular Literaturas e Culturas Lusófonas-I, indique quantos autores ou não conhecia/nunca tinha ouvido falar, assinalando a opção correta 14 respostas

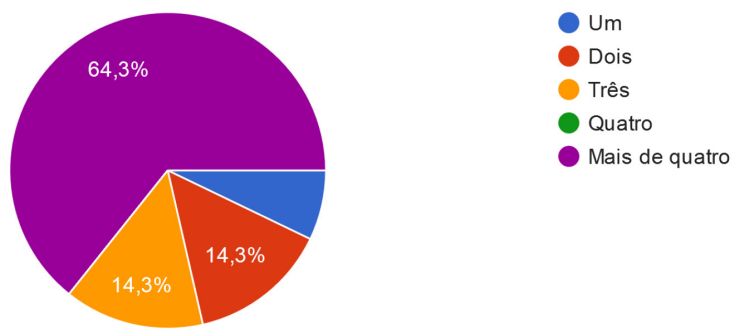

Fig. 3 
8- A avaliação da unidade curricular Literaturas Lusófonas-I passou também pela realização de um trabalho de investigação de um autor Lusófono. Já conhecia o autor cuja obra trabalhou?

14 respostas

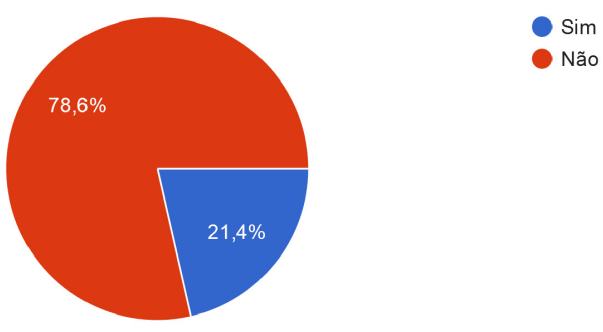

Fig. 4

Concluímos da observação dos diagramas anteriores que os alunos não conheciam a maioria dos autores que foram trabalhados em aula ou cuja vida e obra lhes foi proposta para investigação e análise (Figuras-3,4 e 5).Através deste projeto, contribuímos para que os alunos como leitores assumissem, indubitavelmente, um papel mais ativo e realizassem um maior envolvimento "como condição necessária para a construção dos sentidos textuais e,em consequência, para o prazer na leitura”(Sousa,1996,p.66).

Se alguma dúvida nos restasse, a resposta à última questão, cujo diagrama, abaixo se indica, foi conclusiva.

8.1- Considera que ler e trabalhar uma obra literária, indicada pela docente foi uma mais valia?

14 respostas

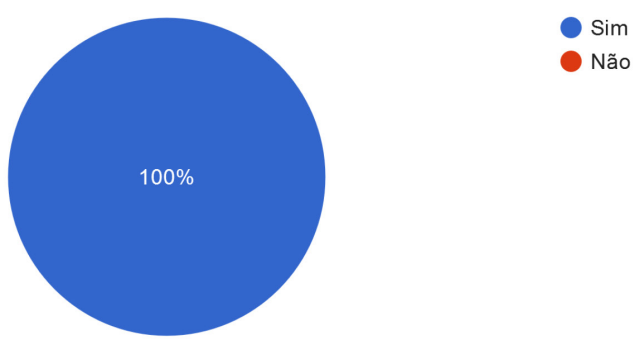

Fig. 5

Apresentamos, seguidamente, algumas das respostas dadas à questão de resposta aberta: “ Na sua opinião qual a utilidade deste projeto?"

"No meu caso passei a conhecer melhor a narrativa do autor e a ganhar mais gosto pela leitura e conhecer muitas palavras novas, a enriquecer o vocabulário." 
"Não podemos estar sempre na nossa zona de conforto, naquilo que sabemos. Temos que tentar sempre descobrir novas coisas e estudar autores recomendados pela professora faznos aprender e descobrir perspetivas novas."

"Foi uma mais valia pois eu não conhecia a obra da autora sugerida e acabei por gostar de ler e adquirir todo o conhecimento que o livro me transmitiu."

“Conhecer escritores e obras de países lusófonos nos dá uma ideia de quem são e nos ajuda a relacionar melhor com as pessoas das comunidades lusófonas.”

"Contribuiu para aumentar a minha cultura geral."

"Ao trabalharmos várias obras literárias, permite-nos um maior conhecimento e cultura geral e é bom saber um pouco dos autores dos vários países lusófonos."

Em jeito de conclusão, acreditamos que este projeto foi bem sucedido porque potenciámos o conhecimento e análise literária de vários autores lusófonos e suas obras mais representataivas, como é fácil comprovar pela observação dos diagramas e respostas apresentados. Subscrevemos integralmente Azevedo (2016), quando afirma que "Comunicar literariamente é permitir aos leitores que se relacionem com o texto literáririo e conduzam essa relação como o desejarem.Educar literariamente é permitir a esses jovens que gostem dele ou o detestem; que com ele construam os seus sentidos, as suas interpretações, as suas representações.Educar literariamente é possibilitar aos jovens uma reação individual, única perante o texto literário, estabelecendo com ele uma relação de diálogo (...)"(p.XIII)

\section{Referências}

Azevedo, F.e Balça,A. (2016). Leitura e educação literária. Lisboa: Pactor.

Barreto, A.(2012). Actas do Colóquio Internacional São Tomé e Príncipe numa perspectiva interdisciplinar, diacrónica e sincrónica (2012), 505-517.Lisboa: Instituto Universitário de Lisboa (ISCTE-IUL), Centro de Estudos Africanos (CEA-IUL).

http://www.dges.mctes.pt/DGES/pt/Reconhecimento/NARICENIC.

Plano de estudos para o Ensino Secundário República de Cabo Verde. (1996).Ministério da Educação, Ciência e Cultura on line (Cons.13-3-2020).

Programa da unidade curricular Literaturas e Culturas -Lusófonas-I on line (Ano letivo de 201972020).Instituto Politécnico de Bragança. (Consultado 15/2/2020).

Sousa, M.L.D.(1996).Agora não posso.Estou a ler!.In R.V.Castro \& M.L.D Sousa, Entre linhas paralelas:estudos sobre o português nas escolas.Braga: Angelus Novus,pp.55-70. 